\title{
The Global Economic Impact of Terrorism
}

\section{Dumitru-Mihai Luca}

Faculty of Economics and Business Administration, M „Alexandru Ioan Cuza” University of Iași, Romania

\section{Abstract}

In general, when analyzing the costs of armed conflict, the literature most often relates to civil wars or interstate conflicts. The moment of September 11, 2001 marked the beginning of a new concern in the economy, namely the economic cost of terrorism. Terrorism is a form of conflict in which acts of violence are directed at non-combatants or civilians who are usually unrelated to the political target of the group that committed it. This article analyzes existing data on the costs of terrorist acts that are committed by nonstate parties or subnational groups. In this article, we will also look at the impact that terrorism has on the world economy (including both developed and underdeveloped states). We will find that although it has a significant impact on the global economy, the most devastating effects of violence are felt by underdeveloped economies whose poverty and inequality do not allow for a rapid and sustained response to terrorism.

Keywords: terrorism, economy, cost, impact, violence

\section{Introduction}

It is a well-known fact that terrorism as a phenomenon, through its destructive effects, harms the quality of individual life, having repercussions on the growth and economic development of the attacked state. In recent years, terrorism is perceived as one of the greatest threats to the Western world, with globalization giving terrorist groups access to more and more countries. Also, the fact that state borders are much easier to cross has made the threat from terrorist groups a general one, and the attacks to be on the rise. In recent years, a number of major terrorist attacks in EU Member States have put the fight against domestic and international terrorism at the top of the European counter-terrorism agenda. A very important aspect is that the attacks took place not only in European capitals but also in peripheral territories, belonging to EU Member States. According to data provided by Global Terrorism (2017), 2016 was the most violent year for Europe: 630 terrorist attacks took place, resulting in 826 victims. For terrorists, the most targeted countries in the European Union are France, Spain, the United Kingdom and Germany. However, if we refer to 
the whole of Europe, Turkey has experienced most of the attacks, which indicates that the European Union is still a relatively safe place.

From an economic point of view, terrorist incidents impose high costs on the persons and countries attacked, in the literature many authors claiming that the negative effects of terrorism are substantial. In this article we will refer to two major costs groups: direct costs and indirect costs. In short, direct costs of terrorism refer to the costs incurred in caring for the wounded and the cost generated by the loss of human lives, but also to the suffering caused to the relatives and friends of the wounded or deceased. Direct costs also refer to the loss of physical capital through the destruction resulting from a terrorist attack. The destruction of some national heritage buildings, symbols of the affected cities can have aggravating consequences both psychologically and economically. On the other hand, indirect costs arise primarily from the disruption of the socio-economic order caused by terrorism. For example, insurance policies for losses due to terrorist activity can become more expensive. Also, victims of terrorist attacks can bear indirect costs such as loss of productivity, loss of income sources both for themselves and for the state. Another indirect cost, impossible to neglect, is the psychological trauma that people experience in relation to terrorist attacks. Being an inherent effect resulting from terrorist actions, the fear tends to divert public resources from productive sectors, generating income to nonproductive sectors, respectively to security and defense. It is no surprise that the share of government spending increases when terrorist attacks occur. This is due to the fact that total public spending on defense and security is increasing. In order to be able to spend more on security, countries either increase taxes or redirect their programmed budget expenditures from supporting revenue-generating sectors to defense and security expenditures that not only do not generate revenue directly but are detrimental to long-term economic growth.

Countries or regions that are heavily dependent on tourism have been found to suffer significant economic losses due to the persistence of terrorism. Terrorism can also reduce the flow of foreign direct investment. Trade relations and consumption can also be affected by the presence of terrorism, as transactions are more difficult, requiring additional security to cover the risks involved. The immediate negative impact generated by terrorism on import-export activities and tourism almost immediately generates an increase in unemployment, which, in turn, implies a decrease in income and, implicitly, in consumption. Such a situation may in turn have multiplier effects, as reduced demand leads to lower production, rising unemployment, declining investment and a general slowdown in economic activity.

In this article we shall present, with the help of information and data found in the literature, how the economy is affected by terrorism, presenting the types of costs involved in these violent acts, while highlighting, globally, the countries most affected by this phenomenon, as well as the least affected. 


\section{Literature review}

Following the widely used definition by Enders, Sandler, and Gaibulloev (2011: 321), terrorism can be seen as "the premeditated use or threat of using violence by subnational individuals or groups against non-combatants to achieve a political goal, or socially, by intimidating a wide audience beyond that of the immediate victims". Broadly speaking, terrorism is a short-term plan implemented to achieve certain long-term political, economic or social goals, which could not normally be achieved in a non-violent way. Schelling (1991) argues that terrorist acts are a means of obtaining, in addition to media attention as a form of communication with the general public, economic and political destabilization. Given the purpose of terrorist organizations to economically destabilize the attacked state, the role of the attacked government is to assess and choose between the cost of accepting the demands of terrorist attackers (i.e. the socio-political objectives at stake) and the cost of a prolonged terrorist campaign. resulting from continued resistance from the government (Sandler and Enders 2008). The efficiency or inefficiency of terrorism is the result of the strategic interaction between terrorists with their enemies, i.e. with governments and security forces.

The literature has identified five ways in which the economy is affected by terrorism: through destruction, disruption, diversion, waste, and portfolio replacement.

Destruction is a direct cost of terrorism because through terrorism, capital is destroyed. Important models of economic growth, such as the Swan-Solow model, show that the production of an economy is a direct result of existing capital; the more capital an economy has, the more that economy will produce. Consequently, when terrorism destroys this stock of capital (for example, by killing people - human capital - or by destroying buildings or infrastructure), production will shrink.

Disruption, diversion, waste and replacement of the portfolio are indirect costs of terrorism, which arise with the response of economic agents to terrorist events. The effect of disruption refers to the negative effects of terrorism on the socio-economic life of a country, i.e. the disruption of the socio-economic order. In general, this disruption of socio-economic life is expected to hamper economic transactions due to the fact that terrorism induces a decrease in trust in public institutions (Arvanitidis, Economou and Kollias 2016). In a non-violent environment, sound public institutions facilitate economic transactions through business costs (so-called transaction costs); if confidence in institutions decreases, transaction costs increase, which leads to noncompletion of economic transactions. For example, (Bird, 2008) concluded that the uncertainty generated by terrorism can lead to long-term investment delays and, taking into account the Swan-Solow model mentioned above, a reduction in investment (or capital) leads to a decrease in output.

Deviation refers to the changes that occur in the allocation of public resources. Specifically, in the case of violent events, public resources are moved from productive, income-generating sectors to non-productive sectors. The affected productive sectors 
may be education and infrastructure which are disadvantaged, the resources allocated to them being used to increase security. Such a decision has a negative longterm impact because the diversion of resources from productive to non-productive sectors prevents economies from accumulating capital.

Waste (de-saving) refers to a decrease in savings that affects the capital of an economy. Again, a lower capital stock (or a lower rate of capital accumulation) leads to a decrease in output and, consequently, to a slowdown in economic growth. Terrorism discourages saving through the psychological impact it has on people. For example, following a terrorist attack, people will analyze the decision on available funds, choosing between saving or consuming, and because terrorism reduces the likelihood of benefiting in the future, individuals may be less inclined to save and more inclined to consume (Naor 2015).

Finally, on the replacement / substitution of the portfolio Abadie and Gardeazabal (2008) argue that terrorism negatively affects the ability of an economy to absorb investment, as it poses a risk and reduces the return on investment. A sudden withdrawal of capital adversely affects economic development, especially when foreign capital is the main driver of economic growth. This often happens in developing economies.

The Institute for Economics \& Peace (2018) estimates the economic impact of violence using an aggregation of costs related to violence, conflict and violencerelated costs. This model uses variables that include both the costs of preventing violence and the costs of the consequences of violence.

Therefore, the variables that form the cost of violence according to the Institute for Economics \& Peace (2018) are structured as follows:

1. Prevention-oriented security services and costs:

- Military expenses;

- Expenditure on ensuring internal security;

- Expenditure on intelligence services;

- Peacekeeping by the UN.

2. Costs related to armed conflicts:

- Direct costs of deaths from violent internal conflicts;

- Direct costs of deaths from violent external conflicts;

- Indirect costs of violent conflicts resulting from the loss of potential investments and infrastructure to be rebuilt;

- Restricting the import of weapons affecting the military sectors;

- Terrorism.

3. Costs related to interpersonal violence:

- Homicide;

- Fear of murder;

- Indirect incarceration costs. 
At the same time, the economic impact of violence includes the direct costs that are the cost of violence for the victim, perpetrator and government (these include direct costs, such as police costs) and indirect costs that accrue after the violent event and include indirect economic losses, physical trauma. and physiological for the victim, the decrease and loss of productivity, as well as the loss of investors for the affected states.

\section{Methodology}

For the period analyzed in this article, the economic impact of terrorism is calculated using the violence cost methodology of the Institute for Economics \& Peace, (2018). Therefore, the model used to calculate the impact of global terrorism includes the direct and indirect costs caused either by the number of victims or deaths or by the destruction of property resulting from jihadist actions.

An important variable when talking about the impact of terrorism on the economy is the level of development of countries affected by terrorism. Thus, in this article, in order for the data to be presented as correctly as possible and to be able to take into account the income differences between states, unit costs are calculated according to GDP relative to the number of inhabitants. Statistical information related to terrorist actions will be used in the Global Terrorism Database which are also found in the reports of the Institute for Economics \& Peace, (2015 - 2019) this information being collected by the "National Consortium for the Study of Terrorism and Responses to Terrorism" (START). The data obtained from these databases show the number of deaths, casualties for each incident, as well as the extent of the damage and destruction resulting from these terrorist attacks.

\section{Analysis of the economic costs of terrorism}

First of all, we believe that it is necessary to define direct and indirect costs. Thus, direct costs are those costs that are borne by the victims of terrorist acts, such as medical expenses, provided that these expenses are borne at the same time by the government. As far as the state is concerned, the expenses are directed in maintaining security by ensuring the salaries of the military personnel engaged at that time as well as for the equipment used. At the same time, another direct cost that can result from terrorist actions are those related to the restoration of destroyed properties and goods, but also to the restoration of public and critical infrastructure.

As for indirect costs, in the case of victims, they are associated with the loss of work capacity, which implicitly leads to the loss of jobs and a stable income. In addition to the loss of work capacity, the population exposed to terrorist events may also face psychological traumas over time. As for the state, indirect costs translate into lower tax collection, lower investment whether we are talking about local investment or foreign direct investment and losses generated by the relocation of funds from productive sectors to non-productive ones necessary to ensure security. These costs have a different impact on economies, with developed ones having a higher resilience than states facing political, economic and social problems. 
An important indicator, when we talk about terrorism, is its economic impact worldwide. Thus, we submitted to the study the period 2000-2018, in order to highlight the evolution of the economic impact of terrorism as well as the possible causes that generated its increase / decrease, the analyzed data and conclusions can be observed from the chart and comment below:

Chart no. 1 - The economic impact of terrorism worldwide in the period $2000-2018$ (billions \$).

The economic impact of terrorism 2000 - 2018

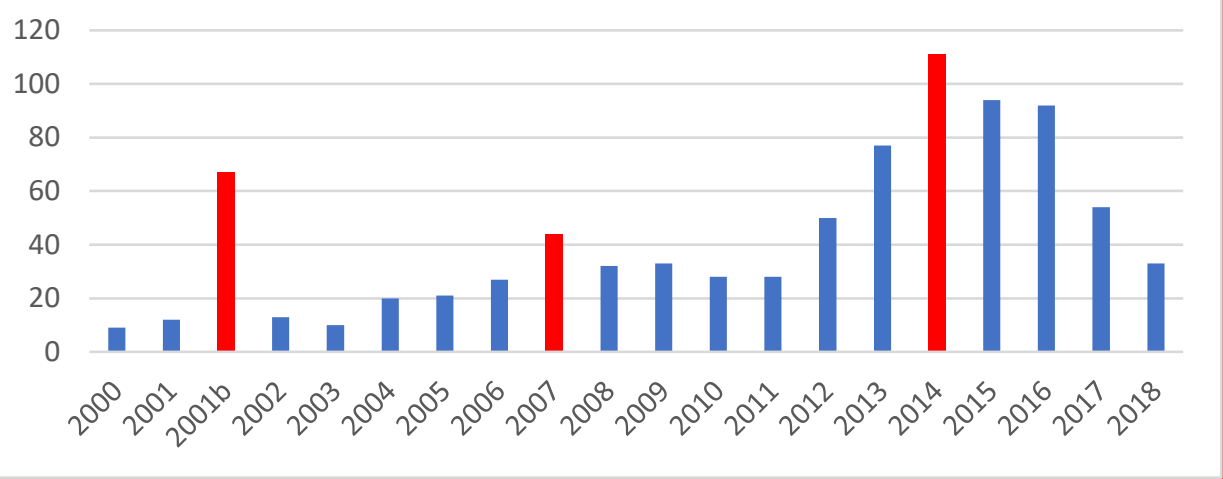

Source: Own processing according to the report of the Institute for Economics \& Peace: Global Terrorism Index 2019, page. 29

The chart above illustrates three "critical" moments for the economy, determined by the evolution of terrorism. Thus, the first major increase in the economic impact of terrorism occurred on September 11, 2001, marking the beginning of a war between the West and terrorist organizations. In 2001, out of a total of $\$ 79$ billion representing the impact of terrorism on the global economy, $\$ 67$ billion meant only the attacks on the Twin Towers and the Pentagon, a figure that is still the highest cost of terrorism associated with a single event.

The second great moment was recorded in 2007, although, until this second wave, there were also attacks in Madrid, in 2004 but also in London, in 2006. The increase of the economic impact on terrorism, in 2007 , which amounted to about $\$ 44$ billion, is mainly attributed to Al Qaeda-affiliated terrorist groups, and also coincided with an increase in the presence of coalition troops in Iraq and Afghanistan.

The third wave of increasing the impact of terrorism on the economy began in 2012, continuing with the terrorist attacks recorded in 2013 in Boston, in 2015 in Paris, in 2016 in Brussels, in 2016 in Nice, but also many other attacks. made in countries such as Iraq, Afghanistan or Syria. The year 2014 has the highest level of impact that terrorism has on the global economy, being estimated at about 111 billion dollars, thus exceeding the 79 billion dollars level reached in 2001. The global economic impact of terrorism reached the amount of 94 billion dollars in 2015, which 
experienced a slight decrease compared to 2014, the level being lower by about $15 \%$, this being also reflected in the decrease in the number of people killed by this phenomenon. The economic impact of terrorism in 2015 has been at the second largest level since the early 2000 s.

From 2016 to 2018, the size of terrorism is slightly declining, with the impact on the world economy accounting for $\$ 92$ billion in 2016, $\$ 54$ billion in 2017, half the value of the damage caused in the year 2014, which is also the top of the "pyramid", and \$ 33 billion global economic impact of terrorism calculated for 2018, registering a decrease of $38 \%$ of the economic impact of terrorism compared to 2017. These figures are "gratifying", given the proportions of this phenomenon, any index that reflects a decline in terrorism is a victory for the West and for those who want peace and economic, political and social stability. However, it should be noted that all these figures are estimates because it is difficult to quantify the total cost of all elements affected by terrorism. In essence, these costs include the long-term economic implications of terrorism in economic sectors such as tourism which is an economic sector sensitive to such events, reducing the business environment, investment and production, leading to the channeling of funds from productive sectors to insurance sectors. and maintaining national security and not adding direct value to the economy. The decrease in terrorist events in recent years, illustrated in the chart above, is associated, by some security experts, with the decline of ISIS power in the main areas of controlled conflict. Thus, military interventions, increased security measures and risk awareness by the Iraqi and Syrian governments fighting terrorism have led to the deterrence of terrorist organizations such as ISIS and Al-Qaeda.

If we were to make a ranking of the countries most affected by violent acts such as terrorism, we will notice that often the countries suffering from armed conflicts and implicitly terrorism also face the costliest economic effects due to this phenomenon. Such countries are located in the Middle East, North Africa or South Asia and at the same time coincide with a low level of development. In chart number 2 we included the first 12 states that for 2015 and 2017 recorded the highest economic cost of violence. These costs are represented by the cost of violence for the victim, perpetrator and government (these include direct costs, such as the cost of police) and indirect costs that accrue after the violent event and include indirect economic losses, physical and physiological trauma for the victim, decrease and loss. productivity, as well as the loss of investors for the affected states. 
Chart no: 2 - The top of the states with the highest cost of violence in the economy for 2015 and 2017, values expressed as\% of GDP.

\section{ECONOMIC COST OF VIOLENCE IN 2015 - 2017 (\% OF GDP)}

ロ $2015 \square 2017$

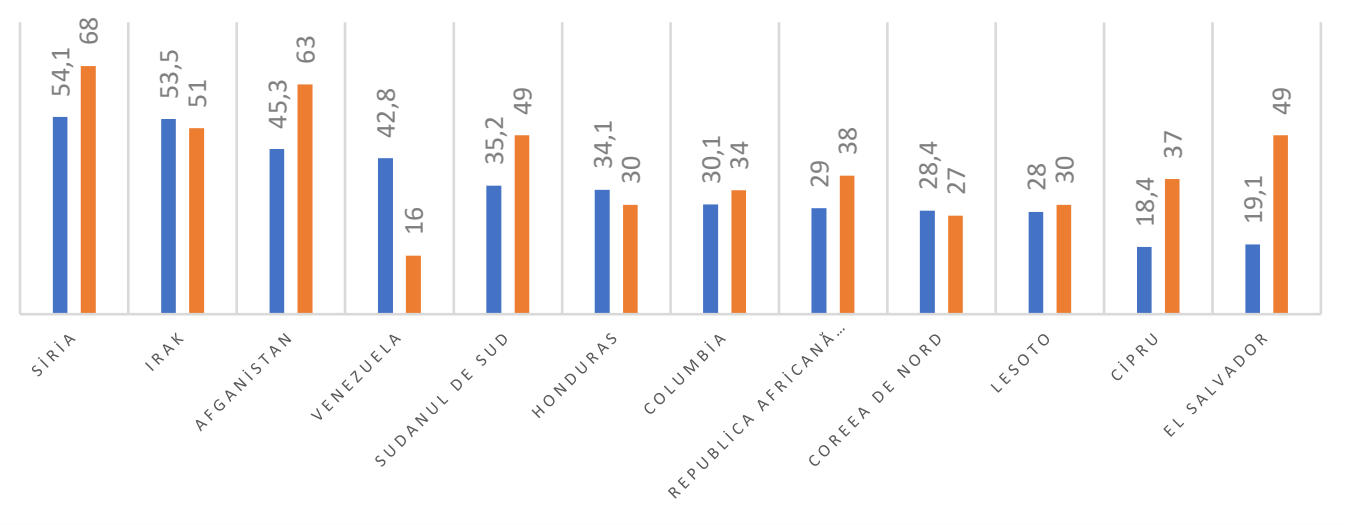

Source: Own processing according to the reports Institute for Economics \& Peace: Economic Value of Peace 2016 - page 12; EVP 2018 - page 11.

The graph above highlights the evolution of the economic cost of violence for the most affected states in the world, in 2015 and 2017. The states included in this analysis face high levels of interpersonal violence and armed conflict. Thus, the states affected by armed conflicts are Colombia, the Central African Republic, Somalia, South Sudan, which have high costs that are caused by injuries and deaths caused by civil conflicts, displacement and terrorism. Along with these, the top is completed by a "podium" consisting of Syria, Iraq and Afghanistan, whose economic cost of violence for the period under review is between $45 \%$ and $68 \%$ of GDP. It should be noted that in the three leading states, armed conflicts are mainly caused by terrorist organizations fighting against Western organizations and states present for the restoration of public order and peace. On the other hand, the chart above also shows states such as Lesotho and El Salvador, where the economic cost of violence for these states is associated with higher levels of violent crime and homicide. Instead, Cyprus is an "exception"; the presence of this state in a "negative" top is caused by the fact that much of the economic cost is closely related to the internal displacement of its population and the presence of refugees. Also, in the case of the state of Cyprus, the increased economic cost of violence is due to the fact that the Nicosia government has been overtaken by the number of refugees arriving in a relatively short time. Thus, the level of spending on the violence prevention sectors has increased in order to maintain a balance that ensures public confidence in the political, economic and social environment. 
From the chart above, we can see a general negative evolution for 2017 compared to 2015, except for some countries such as Honduras or Venezuela which have managed to apply some corrective measures to reduce the economic cost expressed as a percentage of GDP. In 2015, Venezuela had an economic cost of violence of $42.8 \%$ of GDP, so by implementing policies to combat violence, this state reduced its percentage to $16 \%$ in 2017; a significant evolution, being the lowest percentage of the top for 2017. The rest of the states included in the analysis experienced a negative evolution, the economic cost increasing, which proves that the policies and measures identified and applied by Western organizations and states must be customized, for each state.

At the opposite pole, in chart number 3, we included the states that recorded the lowest cost of violence, for the period 2015-2017.

Chart no: 3 - Top of the states with the lowest cost of violence in the economy for 2015 and 2017, values expressed as\% of GDP.

\section{ECONOMIC COST OF VIOLENCE IN 2015 - 2017 (\% OF GDP)}

\section{$2015 \square 2017$}

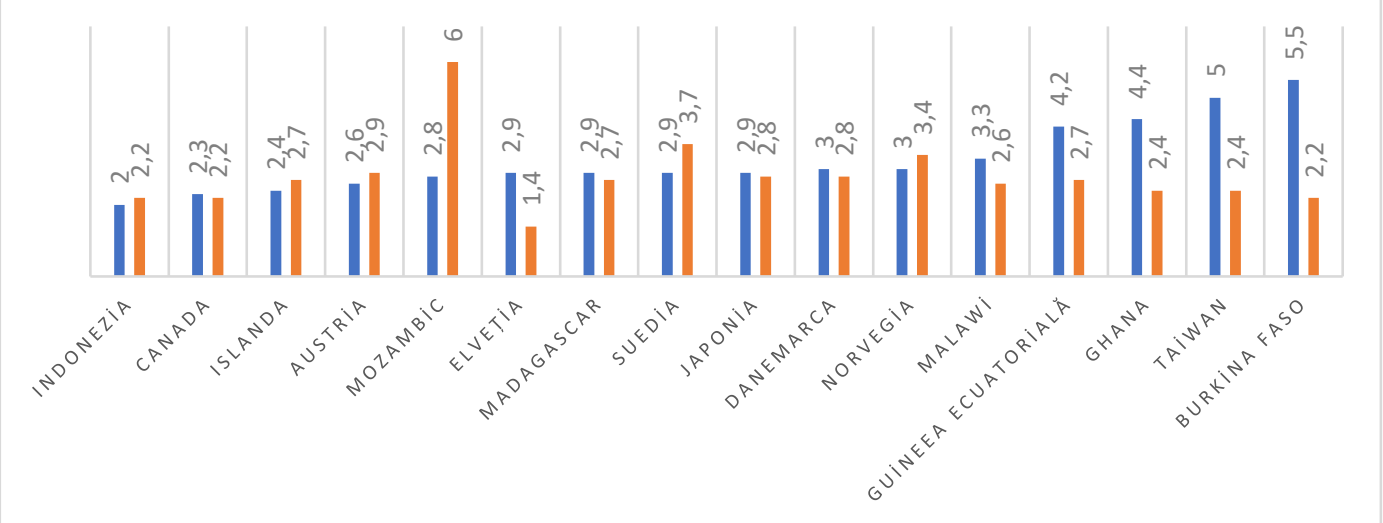

Source: Own processing according to the reports Institute for Economics \& Peace: Economic Value of Peace 2016 - page 44 - 47; EVP 2018 - page 31 - 33.

The chart above shows us the states most bypassed by terrorist actions and which bear the lowest costs of violence for 2015 and 2017. The average economic costs associated with violence as a percentage of GDP for the analyzed period is about $3.05 \%$. This average is significantly lower than the global average, which in 2017 represented about $11 \%$ of GDP. The average military costs in 2017 is $1.2 \%$ of GDP, compared to the global average of $2.1 \%$ of GDP. The lowest military expenditures are recorded by the states of Madagascar, Switzerland and Indonesia, these costs being $0.6 \%, 0.7 \%$ and $0.8 \%$ of GDP respectively. A similar trend as that of military costs is 
given by the costs necessary to ensure internal security, so the countries with the lowest expenditures directed to this area of interest are Switzerland with only $0.2 \%$ of GDP (this is also due to the position of neutrality which this state has compared to the rest of the world), Equatorial Guinea with $0.36 \%$ and Indonesia with $0.4 \%$ of GDP.

\section{Conclusions}

In relation to those presented, we can say that forms of violence such as terrorism are a real problem, which continues to be more and more present. Based on the data analyzed, we can say that developed countries suffer less damage from terrorism than underdeveloped economies, due to the fact that developed countries have the ability to ensure better security and a faster response to violent acts. It has been observed that the economic impact of violence, which includes terrorism, has a devastating impact on poorly developed economies such as Syria, Iraq, Afghanistan, etc., accounting for over $50 \%$ of the GDP of the affected economy. On the other hand, in developed economies, capable of implementing increased security measures, the impact of violence on economies is not so significant, with a few exceptions exceeding $5 \%$ of GDP.

A solution to reduce violent events and terrorism can come even from the governments of the states concerned, which, in order to avoid violent acts, should avoid political, economic and social discrimination among minorities. At the same time, in order for vulnerable states to avoid violent manifestations, it is necessary to implement effective security measures which, although in the short term may represent an unjustified economic cost, can show their long-term benefits.

\section{References}

[1] 1.Abadie, A., \& Gardeazabal, J. (2003). The Economic Costs of Conflict: A Case Study of the Basque Country. The American Economic Review, 113 132.

[2] 2.Arvanitidis, P. E. (2016). Terrorism's effects on social capital in European countries. Public Choice 169 (3), 231-250.

[3] 3.Bird, G., Blomberg, B., Hess, G. (2008). International terrorism: Causes, consequences and cures. World Economy, 273.

[4] 4.Gaibulloev, K., Sandler, T. (2008). Growth Consequences of Terrorism in Western Europe. Kyklos, 411-424.

[5] 5.Gupta, S., at el. (2004). Fiscal consequences of armed conflict and terrorism in low- and middle-income countries. European Journal of Political Economy, 403-421.

[6] 6.Hobijn, B. (2003). What Will Homeland Security Cost? Economic Policy Review, 21-33.

[7] 7.Institute for Economics \& Peace. (2016). The Economic Value of Peace 2016. Sydnei: Institute for Economics \& Peace.

[8] 8.Institute for Economics \& Peace. (2017). Global Terrorism Index 2017: 
Measuring and understanding the impact of terrorism. Sydnei: Institute for Economics \& Peace.

[9] 9.Institute for Economics \& Peace. (2018). The Economic Value of Peace 2018. Sydnei: Institute for Economics \& Peace.

[10] 10.Institute for Economics \& Peace. (2019). Global Terrorism Index 2018: Measuring the impact of terrorism. Sydney: Institute for Economics \& Peace.

[11] 11.Llussa, F., Tavares, J. (2008). Which Terror at Which Costs? On the Economic Consequences of Terrorist Attacks. Lisbon: University of Lisbon.

[12] 12.Naor Z. (2006). Untimely death, the value of certain lifetime and macroeconomic dynamics. Defence and Peace Economics, 343-359.

[13] 13.Navarro P., Spence A. . (2001). September 2001. Assessing the Costs of Terrorism. Milken Institute Review, 16-31.

[14] 14.Sandler, T. E. (2008). Economic Consequences of Terrorism in Developed and Developing Countries . In P. Keefer \& N. Loayza (Eds.), Terrorism, Economic Development, and Political Openness (pp. 17-47). Cambridge: Cambridge University Press.

[15] 15.Schelling, T. (1991). What Purposes can "International Terrorism" Serve? In R. Frey \& C. Morris (Eds.), Violence, Terrorism, and Justice (Cambridge Studies in Philosophy and Public Policy, pp. 18-32). Cambridge: Cambridge University Press.

[16] 16.Wouter van Ballegooij \& Piotr Bakowski. (2018). The fight against terrorism - Cost of Non-Europe Report. Bruxelles: European Parliamentary Research Servic. 